\title{
The Reelection Issue and the Optimal Duration of Presidential Terms
}

\author{
Dr Gabriel Turbay \\ Ph.D. in Mathematical Sciences, RiceUniversity, Houston Texas, \\ President of Strategic Game Theory of Economics Science Society, Colombia \\ Giovanni E. Reyes \\ Ph.D. in Economics of Development/International Relations, \\ University of Pittsburgh/Harvard, \\ Full, Tenure Professor Universidad del Rosario, Colombia
}

Doi: $10.1515 / m j s s-2017-0019$

\begin{abstract}
Presidential democratic regimes impose constitutional limits on the duration of the president's term and on the possible occurrence of subsequent reelections. Term limits and reelection restrictions also exist in the government of corporations and firms for the chairman of the board and for the board members. In this paper, an attempt is made to identify what the major reasons for this limitations and restrictions could be. A related archetypical cost structure, also found in Inventory Theory and Waiting Lines Theory, is identified and modeled to study factors such as the cost of corruption, which are key factors in determining the optimal duration for a government term. A game theoretical consideration of corruption and term limitations strategies is presented at the end of the paper.
\end{abstract}

Keywords: Reelection processes, presidential terms, optimal decisions.

\section{Introduction}

Democracies periodically have elections. As opposed to dictatorships and monarchies, the candidates to be elected must declare and promise to serve the general interest during his term. It may be that this commitment to serve the general interest, though it should be assumed, must be declared periodically because for some reason long terms in power for the same government end up in polarization and corruption.

The person in charge is surrounded by a ring of friends and close collaborators which develop an adulatory roll blinding his ability to serve the general interest and filtering and redirecting decisions to favor particular interest. That has been the case in long-term dictatorships like the Shah in Iran, Somoza in Nicaragua, Marcos in Philippines, Duvalier in Haiti, Pinochet in Chile, and countless many others in the recent history of modern democracy. This also appears to be the case with institutional party dictatorships like the communist party in the Soviet Union previous to its dissolution and the PRI in Mexico.

The problem of determining the optimal or close to optimal duration for a presidential term is one that has not been satisfactorily solved in political and administration sciences. Nonetheless most democracies have opted for presidential terms with duration between 4 and 7 years. Turbulence, change and the conformation of a new political environment induced by the forces of Globalization, has prompted in recent years many constitutional reforms. Many of these reforms try to extend the duration of the presidential term when this term is close to the lower bound of 4 years, 
some other to shorten the duration of the term when close to the upper bound of 7 years (Bernales, 1994).

In addition, the re-election component is often proposed in variety of combinations which in some cases is permitted and in other cases is restricted in some way, for example, reducing the period of time from 6 to 4 years and allowing immediate reelection or extending the period from 4 to 6 years and allowing for re-election but not in the immediately following period -not in two consecutive periods (Toonen, 2010; Ansari, 1994).

Thus, term limits is an issue intimately related to the nature of democracy in a financial capital oriented world, it has to do with power separation and the balance of power, with protecting the general interest from particular interest and it definitively has to do with human nature, its weakness and its greatness and the need for the constitutional subordination and limitation of human ambition to principles (Bernales, 1994; Van der Bergh, 2013).

Term duration is also an issue considered in the Corporate Governance guidelines for companies developed by governments and stock exchange organizations. The duration of the term for board members in most groups, corporations and firms range form 1 to 6 years (Adams, 2014; Mandle, 1999). Some views maintain that the term of service must not be limited based on the value of the insight gained by directors through time into the business and operations of the company (Bradenburger, 2011).

Also there exists the view that long terms do not favor the interest of small investors. Some stock exchange organizations recommend short terms of 1 year.

Summarizing, arguments in favor of longer terms identify the value of specific knowledge, learning and experience and also specific costs to be avoided related with frequent elections. The arguments for shorter periods fear the polarization of knowledge and learning to favor particular interest, also fear of stagnation (Buckley, James L. 2000).

In general, for national organizations like the Supreme Court and corporations governance boards, there are both: costs inversely related and costs directly related to the duration of the term. Similarly, reelection is associated with the democratic right that must not be restricted to recognize excellence in government but also with corruption, polarization of power, stagnation and self interest (Bradenburger, 2011).

Cost competition in relation to the duration of the term is an archetype which also occurs in a variety of problems related to inventory theory and in waiting lines theory. These problems have been successfully solved with the help of elementary mathematical optimization theory in management sciences. In particular, a well known solution is the economic order quantity (EOQ) (Bengtsson, 2016).

In terms of methodology it is crucial to keep in mind that mathematical models are not necessarily a simplified view of reality, sometimes they serve to identify key interrelations of elements that conform reality and allow learning from a systematic analysis of the identified archetypical relations. This paper follows the methodological path to consider a mathematical approach regarding the issue of reelection. The main focus is on the nation-state scope of political conditions, but this consideration can be adapted to other kind of leadership such as that of enterprises, for example (Reyes, 2003).

The purpose of this paper is to promote trans-disciplinary work by introducing a mathematical model as a tool to approach and analyze the problem of the optimal duration of terms in government and its relation to re-election. Mathematical models in the social sciences have become an important component of analysis which allows identifying, clarifying and better understanding the relations among the determinant elements concerning social processes events (Hillier, 2004). A contribution from this paper is related to identify structural conditions within social, political and entrepreneurship contexts, which in turn have vital consequences on leadership and the conducting tasks of allocation of resources in any social organization.

\section{Term Duration}

The following table contains a selected sample of countries with non-parliamentary democratic forms of government. The corresponding duration of the presidential term and its relation of 
acceptance with the re-election element is also included (see Table 1).

There is no democracy with a 3- year presidential term or with an 8-year term. From the sample above we can observe that there is no consensus as to what the optimal duration of the term might be, and if reelection is convenient or not, nor there are principles which might suggest the term duration or the reelection issue. The duration of the presidential term and the reelection issue in any particular democratic country appear to be determined by majority vote in trial-anderror processes based on intuitive considerations, and historical events and cultural traditions (Petracca, 1992).

Table 1. Presidential terms in selected countries with non-parliamentary democratic forms of government

\begin{tabular}{|c|c|c|c|}
\hline COUNTRY & $\begin{array}{l}\text { TERM } \\
\text { (Years) }\end{array}$ & REELECTION & $\begin{array}{c}\text { CONSECUTIVE } \\
\text { TERMS }\end{array}$ \\
\hline $\begin{array}{l}\text { Argentina } \\
\text { Colombia } \\
\text { United States }\end{array}$ & 4 & $\begin{array}{l}\text { YES } \\
\text { YES } \\
\text { YES }\end{array}$ & $\begin{array}{l}\text { YES } \\
\text { YES } \\
\text { YES }\end{array}$ \\
\hline $\begin{array}{l}\text { Germany } \\
\text { Brazil } \\
\text { Uruguay }\end{array}$ & 5 & $\begin{array}{l}\text { YES } \\
\text { YES } \\
\text { YES }\end{array}$ & $\begin{array}{l}\text { YES } \\
\text { NO } \\
\text { NO }\end{array}$ \\
\hline $\begin{array}{l}\text { Austria } \\
\text { México } \\
\text { Chile }\end{array}$ & 6 & $\begin{array}{l}\text { YES } \\
\text { NO } \\
\text { NO }\end{array}$ & $\begin{array}{l}\text { YES } \\
\text { NO } \\
\text { NO }\end{array}$ \\
\hline $\begin{array}{l}\text { France } \\
\text { Italy } \\
\text { Kazakhstan }\end{array}$ & 7 & $\begin{array}{l}\text { YES } \\
\text { NO } \\
\text { YES }\end{array}$ & $\begin{array}{l}\text { YES } \\
\text { YES } \\
\text { YES }\end{array}$ \\
\hline
\end{tabular}

Source: based on data from the World Bank and United Nations Development Program.

It is interesting to note that the variance of the duration of the terms is relatively small and that it appears to be a general consensus that 1 or 2 year terms are too short a period, and 9 or more years terms are too long.

\section{Cost Analysis}

Let us consider a planning horizon $\mathrm{T}$ to be covered by presidential terms of duration $\mathrm{t}$. If for example $T=36$ years and the presidential term is $t=4$ then during the period in consideration there would have to be $n=9$ elections.

That is, the $n$ number of elections is given by

$$
n=\frac{T}{t}
$$

Clearly if there were presidential elections every year in a given country the campaign costs would be a significant burden to be financed. Also the effectiveness of government would be highly undermined by the fact that the job requires a period of adjustment and learning of specific processes and relations of intervening elements, essential in the decision making of a presidency and one year is barely enough. This last observation is true for any job in any organization (Saporiti, 2004).

Here, two types of costs associated with the number of elections can be identified (Mcdaid, S. (2016). First, there is a cost of the election itself (there are many countries where the costs of the elections are partly subsidized by the State). Second, there is a cost of adjustment aggravated by the fact that a new government represents a new vision promised to the electing constituents and hence there is a tendency to reject the previous government programs giving place to what has 
been identified as the sharks-fin type of stagnation in public administration (see figure below)

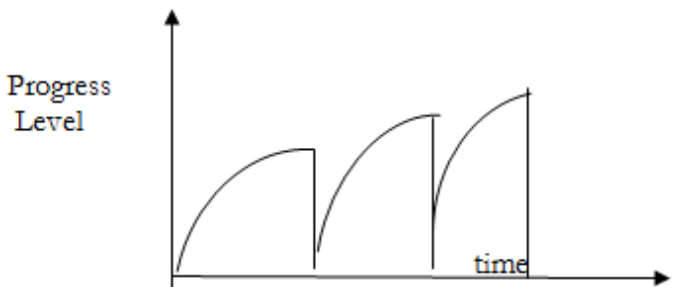

Figure 1: Shark-fin Diagram for Program's Discontinuity

Source: Based on concepts contained in Mueller, Dennis (2003) Public Choice: An Introduction. New York: Springer.

These costs are directly proportional to the number $\mathrm{n}$ of elections and hence inversely proportional to the duration of the term.

Assuming these costs can be computed, then, the total cost associated with the election is:

$\mathrm{C}_{\mathrm{E}}=$ Campaigns Costs + Learning Costs + Lack of Continuity Costs

Therefore in the planning horizon $\mathrm{T}$, the associated total cost is given by

$$
\begin{aligned}
& C_{1}(t)=n \cdot C_{E} \\
& =C_{E} \frac{T}{t}
\end{aligned}
$$

Related to the duration of the term there are costs due to corruption and polarization of power in favor of special interest groups and these costs increase with the duration of the term $\mathrm{t}$. We may assume that corruption drains or diverts the public resources producing an annual loss that increases with time. That is, the losses in a particular year are greater than those of the preceding year (Streb, 2002; Pérez-Liñán, 2016).

This basically means that the cost of polarization and corruption is an increasing function of the term duration $t$. If the incremental losses are assumed to grow linearly at a rate $C_{c}$, then the cost function $c(t)$ would be given by $c(t)=C_{c} t$ (see figure below), and the cost of polarization and corruption during the period of duration $t$ would be given by

$$
\begin{aligned}
& C_{c}(t)=\int_{0}^{t} C_{c} t d t \\
& =\frac{1}{2} C_{c} t^{2}
\end{aligned}
$$

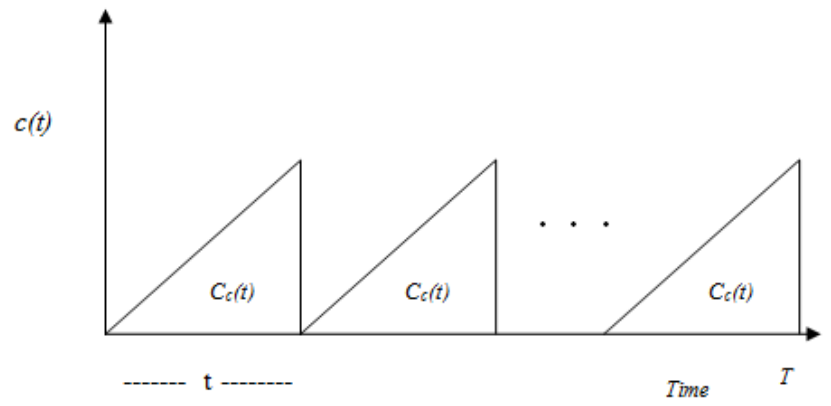

Figure 2: Corruption Costs per Term in the Planning Horizon

Source: Figure 1, and concepts contained in Mueller, Dennis (2003) Public Choice:

An Introduction. New York: Springer. 
The total cost during the ${ }^{n=\frac{T}{t}}$ periods in the planning horizon $T$ is given by:

$$
C_{2}(t)=\frac{1}{2} C_{c} t^{2} \frac{T}{t}
$$

or

$$
C_{2}(t)=\frac{1}{2} C_{c} t T
$$

\section{Optimal Term}

The total cost function for the planning horizon $T$ is given by

$$
\begin{aligned}
& C(t)=C_{1}(t)+C_{2}(t) \\
& =C_{E} \frac{T}{t}+\frac{1}{2} C_{c} t T
\end{aligned}
$$

The derivative of $C(t)$ is

$$
C^{\prime}(t)=-C_{E} \frac{T}{t^{2}}+\frac{1}{2} C_{c} T
$$

the optimality condition $C^{\prime}(t)=0$, gives us

$$
t^{* 2}=\frac{2 C_{E} T}{C_{C} T}
$$

or equivalently

$$
t^{*}=\sqrt[2]{\frac{2 C_{E}}{C_{C}}}
$$

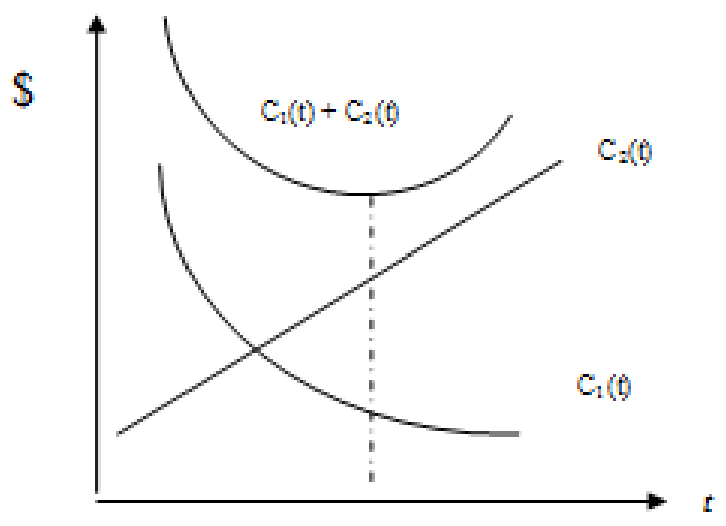

\section{Costs of New Governments and Corruption}

The optimal termed obtained above allows us to estimate the relations that must exist between the cost of inaugurating a new government $C_{E}$ and the corruption cost rate $C_{C}$. For example: 


\begin{tabular}{|c|c|c|}
\hline$t^{*}$ & $t^{* 2}$ & $C_{C}=\frac{2 C_{E}}{t^{* 2}}$ \\
\hline 1 & 1 & $2 C_{E}$ \\
\hline 2 & 4 & $\frac{C_{E}}{2}$ \\
\hline 3 & 9 & $\frac{C_{E}}{4.5}$ \\
\hline 4 & 16 & $\frac{C_{E}}{8}$ \\
\hline 5 & 25 & $\frac{C_{E}}{12.5}$ \\
\hline 6 & 36 & $\frac{C_{E}}{18}$ \\
\hline 7 & 49 & $\frac{C_{E}}{24.5}$ \\
\hline 8 & 64 & $\frac{C_{E}}{32}$ \\
\hline 9 & 81 & $\frac{C_{E}}{40.5}$ \\
\hline
\end{tabular}

Also, it can be observed that

- The optimal duration of the term does not depend on the planning horizon T

- As corruption is reduced, the optimal term duration increases without bound (like may be the case with the Pope's term)

- If the system is operating with an optimal duration term $t^{*}$, reelection would increase total polarization and corruption costs.

- Under the assumptions of this analysis, it becomes clear that corruption and tendency to arbitrary or tyrannical governments would be the major objections to long terms in office. Re-election appears to be a good alternative provided the power and resources of government are not misdirected to secure the re-election. Cyclical management of the economy as related to fiscal and expenditure policies has been associated with reelection. Perhaps, governments with constitutional re-election should consider tight scrutiny for collaborators to continue working with the re-elected president.

- Whenever reelection limitations are eliminated, the constitution must be reformed to maintain an adequate balance of power and to protect the general interest from particular ones

- Since the cost of electing a president plus the learning cost of adapting to a new job environment can be thought of as relatively constant in a given period, the optimal term can be expressed as a function of the corruption level. That is,

$t^{*}=\sqrt{\frac{k^{\circ}}{C_{c}}}=\frac{k}{\sqrt{C_{c}}}, \quad C_{E}=\frac{k}{2}$

The following graph is obtained: 


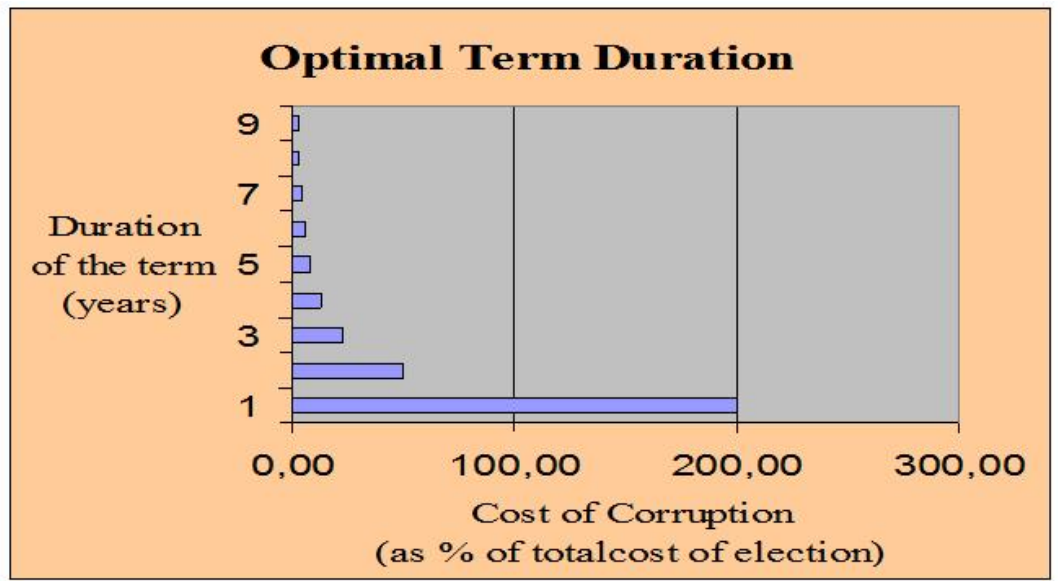

\section{Graph 1:}

Source: this study quantitative procedures.

\section{Game Theoretical Consideration of Corruption and the Duration of Government Term}

The previous argument development was worked out under the assumption that corruption costs increase with term duration. Corruption appears to be endemic to today's democracies and as such it is assumed to manifest itself in an increasing manner as new governments begin to exercise their mandates. It appears that there is a learning process involved in the manifestation of corruption (Schmitt-Beck, 2016).

As a consequence society tends to reduce term duration precisely to curve down corruption costs. Clearly corruption benefits the corrupt people (CP) in that give them money and power, likewise affect negatively common citizens by bending the rules of the game to serve particular interest. It hinders society. Pictured as a zero-sum game, society looses at least what the corrupt ones secure for themselves (Gerber, 2016; Witko, 2016).

Suppose that a corrupt player can select three courses of action where the intensity of corruption can be selected to be high, medium or low and that society can give an extension to the term duration from 4 to 5,6, 7 or 8 years then the following payoff matrix can be examined:

\begin{tabular}{|c|c|c|c|c|}
\hline & & & iety & \\
\hline & 5 & 6 & 7 & 8 \\
\hline High & $* 12.5 \mathrm{C}_{\mathrm{s}}$ & $18 \mathrm{C}_{8}$ & $24.5 C_{8}$ & $32 \mathrm{C}_{\mathrm{s}}$ \\
\hline Medium & $12.5 \mathrm{C}_{\mathrm{s}} / 2$ & $18 \mathrm{C}_{\mathrm{s}} / 2$ & $24.5 \mathrm{C}_{\mathrm{c}} / 2$ & $32 \mathrm{C}_{\mathrm{s}} / 2$ \\
\hline Low & $12.5 \mathrm{C}_{\mathrm{s}} / 4$ & $18 \mathrm{C}_{\mathrm{s}} / 4$ & $24.5 \mathrm{C}_{\mathrm{s}} / 4$ & $32 \mathrm{C}_{\mathrm{s}} / 4$ \\
\hline
\end{tabular}

Notes: $\mathrm{CP}=$ Corrupt people.

The denominators in the medium and low options are simply to indicate the lower intensity of each level. It can be seen that row 1 and column 1 are dominant strategies respectively and hence the upper left corner is a saddle point where $\max _{i} \min _{j}\left(a_{i j}\right)=\min _{j} \max _{i}\left(a_{i j}\right)=a_{11}$, indicating that without 
proper control, corruption has a clear trend to manifest itself at its maximum level. The duration of the term tends to be decreased to the minimum possible level as best response to the presence of corruption.

\section{Conclusions and Final Considerations}

Several conclusions can be drawn from the previous optimality and the game theoretical considerations.

First, long terms are most desirable whenever society has an honest government, which is committed to serve and actually serves the general interest.

Second, corruption whenever it takes place tends to increase with time and manifest at the maximum possible level.

Third, one of society's best responses to corruption practices appears to be the limitation of term duration; even when a society has the risk of changing of corrupt people, that is, starting new cycles of corruption.

Regarding this last point, it is important to consider the influence of social and legal penalties imposed on the corrupt. Exemplary punishments serve as deterrents for continuing corrupt practices.

Thus, reelection may well play the role of the confidence vote in parliamentary systems; if there are signs of honest and efficient government; presumably, people surely will reelect the incumbent government. This amounts to extending the duration of a term whenever the costs of corruption are kept to a minimum.

Reelected governments should have a similar mechanism to evaluate its internal performance to prevent the growth of corrupt practices by some its public servants. Public servants accountability and autocontrol systems at all levels of government may well be the best internal strategies to keep corruption under control. However, corruption is just a symptom or a systemic consequence of the structure of today's society. It cannot be eliminated within the system. To eliminate corruption the system must be redefined.

The game played between Society and Corrupt People is a dynamic one. It has to do with equity and fair play. This game can be played at different recursion levels in society and may affect the different forms of organizations, governments and stakeholder's interest.

To decide in a firm, what the optimal duration of a board of directors term is, one must consider not only the value of experience of board members but also the extent to which long terms may affect negatively the interest of the small investors in favor the particular interest of the big shareholders.

A more general reflection can be centered on the fact that financial capital's particular interest is permeating government decisions and legislative initiatives at a global level, thus creating a structure that favors particular interest. The main challenge of today's world society appears to be, to defend itself from its different forms of government.

This noticeable trend suggests that the game of society versus corruption may well be ended with the collapse of the Nation State and many of its democratic practices. For today's democracies have no meaningful way to decide on the relevant issues that affect the development of society (Dunn, 2015).

The financial capital interest appears to have created a systemic attractor that may be the major source of corruption and is reshaping the world. Interest rates and future discount rates affect the ability of society to develop and implement long range plans for its welfare and sustained development with peace and equity.

These rates hinder the possibilities of cooperation among its members. A new global structure is being defined and society and its primary constituents must play the global game with new emerging rules that are not even partially understood by the players of the game. 


\section{References}

Adams, J., \& Merrill, S. (2014). Candidates' policy strategies in primary elections: does strategic voting by the primary electorate matter?. Public choice, 160(1-2), 7-24.

Ansari, A., Economides, N., \& Ghosh, A. (1994). Competitive positioning in markets with nonuniform preferences. Marketing Science, 13(3), 248-273.

Bengtsson, A.., \& Christensen, H. (2016). Ideals and actions: Do citizens' patterns of political participation correspond to their conceptions of democracy?. Government and Opposition, 51(2), 234-260.

Bernales Ballesteros, E. (1993). Los Poderes Ejecutivo y Legislativo en la Constitución Peruana de 1993. División de Poderes. Buenos Aires, CIEDLA.Bradenburger A., \& Barry J.N. (2011) Co-opetition. New York: Doubleday. Briefing Papers 14, February.

Buckley, J.L. (2000). "Corruption Campaign Finance, and Term Limits" Cato Policy Report March/April 2000.

Dunn, W. N. (2015). Public policy analysis. London: Routledge.

Gerber, A. S., Huber, G. A., Doherty, D., \& Dowling, C. M. (2016). Why people vote: estimating the social returns to voting. British Journal of Political Science, 46(2), 241-264.

Lee, C. K. (2011). The influence on developing countries' foreign direct investment (FDI) policies imposed by incentives: A game analysis. African Journal of Business Management, 5(34), 12015.

Mandle, J., \& Mandle, J. (1999). Elections as a public good. Challenge, 42(5), 50-62.

McDaid, S. (2016). Pragmatists versus dogmatists: Explaining the failure of power-sharing in Northern Ireland during the 1970s. British Politics, 11(1), 49-71.

Mueller, D. C. (2004). Public choice: an introduction. In The encyclopedia of public choice (pp. 32-48). Springer US.

Pérez-Liñán, A., \& Castagnola, A. (2016). Judicial Instability and Endogenous Constitutional Change: Lessons from Latin America. British Journal of Political Science, 46(2), 395-416.

Petracca, Mark (1992). "Why political scientists oppose term limits?", Cato Institute

Reyes, Giovanni (2003) Negociaciones Económicas Internacionales a Partir de Condiciones de Pequeños Mercados Relativos. Nomadas, 9 (3), 55-75.

Saporiti, A., \& Streb, J. M. (2003). Separation of powers and political budget cycles (No. 251). Serie Documentos de Trabajo, Universidad del CEMA: Área: economía ciencia política.

Schmitt-Beck, R., \& Partheymüller, J. (2016). A two-stage theory of discussant influence on vote choice in multiparty systems. British journal of political science, 46(2), 321-348.

Strab, J. M. (1998). Political budget cycles, elections, and term limits.

Toonen, Theo. "Resilience in public administration: the work of Elinor and Vincent Ostrom from a public administration perspective." Public Administration Review 70.2 (2010): 193-202.

van den Bergh, J. C., \& Kallis, G. (2013). A survey of evolutionary policy: normative and positive dimensions. Journal of bioeconomics, 15(3), 281-303.

Witko, C. (2016). The Politics of Financialization in the United States, 1949-2005. British Journal of Political Science, 46(2), 349-370. 